\title{
Effects of Self-Controlled Feedback on Balance during Blocked Training for Patients with Cerebrovascular Accident
}

\author{
Jung-Gyu Yoon, PhD, $\mathrm{PT}^{1)}$, Dong-Won Yook, $\mathrm{PhD}^{2}$, , SAng-Hoon Suh, $\mathrm{PhD}^{2)}$, \\ Tae-Hoon Lee, PhD, MD ${ }^{3)}$, Wan-Hee Lee, PhD, PT ${ }^{4)}$ \\ 1) Department of Physical Therapy, Namseoul University \\ 2) Department of Physical Education, Yonsei University \\ 3) Department of Emergency Medical Service, Namseoul University \\ 4) Department of Physical Therapy, Sahmyook University: 26-21, Gongneung 2-dong, Nowon-gu, \\ Seoul, 139-742, Republic of Korea. TEL: +82 2-3399-1633, FAX: +82 2-3399-1639, E-mail: whlee@ \\ syu.ac.kr
}

\begin{abstract}
Purpose] The purpose of the present study was to examine the effects of self-controlled feedback on the acquisition and retention of blocked balance training by patients with cerebrovascular accident (CVA). [Subjects] Twenty-four hemiplegics were randomly assigned to a self-controlled feedback, yoked feedback or control group. All subjects were ambulatory with or without an assistive device. The self-controlled feedback group was provided with feedback whenever they requested it, whereas the yoked feedback group had no influence on the feedback schedule. All subjects performed 10 acquisition trials per block $\times$ four blocks, and 10 retention trials per block $\times$ two blocks one-day later. The data were analyzed using one-way ANOVA and multivariate ANOVA. [Results] In the body sway amplitudes of acquisition phase which was used, to examine practice effect, the left/right (LR) and anterior/posterior (AP) both the self-controlled and yoked feedback groups were significantly smaller than those of the control group, but no significant differences were found between the self-controlled and yoked feedback groups. In the retention phase, to examine learning effect, the left/right (LR) and anterior/posterior (AP) body sway amplitudes of the self-controlled group were significantly smaller than those of both the yoked feedback and control groups. [Conclusion] These results are interpreted to mean that, for hemiplegic patients, self-controlled feedback is a more effective way of restoring balance than yoked feedback.

Key words: Self-controlled feedback, Balance, Cerebrovascular accident
\end{abstract}

(This article was submitted Aug. 26, 2012, and was accepted Sep. 4, 2012)

\section{INTRODUCTION}

The normal postural control system incorporates information from visual, vestibular, and proprioceptive/ somatosensory inputs. Integration of afferent information from these systems allows stable upright posture. A deficiency in any of these systems can lead to instabilities ${ }^{1)}$. Balance problems are common to many diverse groups of patients with neurologic disease or damage, including those who have sustained cerebral infarcts. Previous studies have shown that there is a high correlation between balance and locomotion $^{2,3)}$.

The term "hemiplegia" describes paralysis of one side of the body. Individuals with hemiplegia frequently bear most of their body weight on their unaffected lower extremity, and show a distinct asymmetry in stance and weight bearing ${ }^{3-5)}$. The ideal objective of functional rehabilitation for hemiplegic patients following cerebrovascular accident (CVA), is a reduction in the asymmetrical nature of movement patterns ${ }^{5,6}$. During the stance phase of the gait cycle, a hemiplegic patients typically demonstrates relatively limited weight transfer to the affected limb ${ }^{7,8)}$ Furthermore, when asked to stand comfortably or straight, hemiplegic patients tend to place more weight on their unaffected than on their affected lower extremity ${ }^{9-11)}$. Asymmetry in weight bearing is mainly responsible for falls by hemiplegic patients, who experience at least one fall during the first six months after CVA. The causes of these falls are mainly lack of control when weight is shifted to the affected lower extremity ${ }^{8,12)}$. Mizrahi et al. ${ }^{13)}$ reported the percentage of body weight on the unaffected lower extremity was approximately $70 \%$ of the total body-weight. Bohannon et al. $\left.{ }^{9}\right)$ and Dickstein et al. ${ }^{14)}$ demonstrated that approximately $80 \%$ of hemiplegic patients favoured their unaffected lower extremity for carrying their body weight. Asymmetric weight bearing contributes to gait abnormalities. If asymmetry of the weight bearing is not taken into account, abnormal gait patterns might become habitual and patients would develop learned non-use syndrome ${ }^{15)}$.

Recently, physical therapy and motor learning have begun to be incorporated intotherapeutic plans for effective exercise $^{16,17)}$. Motor learning has been described as the set 
Table 1. Subject characteristics

\begin{tabular}{llrl}
\hline Characteristics & Classification & Number(\%) & Mean \pm SD(Range) \\
\hline \multirow{2}{*}{ Sex } & Male & $18(75.0)$ & \\
& Female & $6(25.0)$ & \\
& Sum & $24(100.0)$ & \\
Involved side & Left & $13(54.0)$ & \\
& Right & $11(46.0)$ & \\
Age (yr) & Sum & $24(100.0)$ & \\
Prevalence time (month) & & & $58.1 \pm 11.60(53.2-63.0)$ \\
Length difference (cm) & & & $21.7 \pm 6.50(19.0-24.5)$ \\
Height $(\mathrm{cm})$ & & & $0.9 \pm 0.57(0.7-1.1)$ \\
Weight $(\mathrm{kg})$ & & & $63.7 \pm 8.92(60.0-67.4)$ \\
\hline
\end{tabular}

of processes associated with practice or experience leading to relatively permanent changes in the capability to perform skilled action. The broadest definition of feedback in motor learning includes all the sensory information that is available as the result of a movement that a person has made ${ }^{18)}$. The early stage of motor learning concentrates of changing the performance of motor tasks. However, many researchers have recently reported that the learning and the performance must be differentiated ${ }^{16)}$. It has been demonstrated that even if performance ability during the practice period is high, it does not necessarily mean that the learning ability is high. In addition, some researchers have insisted that verification of motor learning must be evaluated by a retention or transfer test $^{16,17,19)}$. Effective learning can be achieved by interaction among the elements noted above. Particularly, in the learning process, teachers and therapists need to be interested in how actively subjects participate in the practice ${ }^{20,21)}$.

Recent studies have demonstrated that training protocols incorporating some forms of self-control can be effective in motor skill learning ${ }^{22,23)}$. In studies of self-controlled feedback, learners decide when they want to receive feedback about their movement in a motor task. In other words, participants in the self-control group are informed that they have to control their feedback frequency; that is, they would not receive feedback unless they requested $i^{24)}$. Self-regulation strategies contribute to a perception of self control which has been shown to enhance learning through deeper information processing. Studies of educational and cognitive psychology have indicated that this deeper level of information processing is achieved by giving learners the opportunity to be actively and independently affected in the learning process through the use of self-regulating strategies. By actively involving learners in the learning process and giving them control over at least some aspects of the learning environment, retention of crucial information can be significantly enhanced ${ }^{25)}$.

Janelle et al. ${ }^{20)}$ showed that self-controlled feedback in learning the task of throwing a ball with the non-dominant hand was more effective than yoked feedback or summary feedback. Chiviacowsky et al. ${ }^{22)}$ reported that the error rate of a self-controlled group in a key push task on a computer key-board decreased more than that of a yoked feedback group. In addition, Wulf et al. ${ }^{24)}$ indicated that acquisition of ski movement in a self-controlled feedback group was better than that in a yoked feedback group in motor learning on a ski simulator. Janelle et al. ${ }^{20)}$ reported that this is because subjects participate in the training more actively when using self-controlled feedback, and the perception of the training improves.

Although many studies of feedback training for patients with CVA have enabled researchers to gain insight into the importance of different types and schedules of feedback learning processes, most research in this area has focused on the feedback provider and has ignored resources brought to the learning environment by the feedback processor. In other words, the active roles of the learner have not yet been studied.

Therefore, the purpose of the present study was to examine the effect of self-controlled feedback, that a learner makes a recognition strategy by oneself, on the acquisition and retention of blocked balance training by patients with CVA.

\section{SUBJECTS AND METHODS}

Twenty-four patients with hemiplegia due to cerebrovascular accident participated voluntarily in this study. Prior to the experiment, the purpose and methods of the experiment were explained to them in plain terms. All subjects provided their informed consent and the study protocol was approved by Namseoul University. The subjects met the following inclusion criteria: hemiplegia caused by stroke or traumatic brain damage, physiological problems that would have influenced balance or walking, no walk, orthopedic problems would have interfered with walking, ability to walk independently for more than 30 minutes without the help of another person at least 3 months from the onset of CVA, better than fair grade by MMT (manual muscle testing), muscle tone lower than grade 2 on the Modified Ashworth Scale, and the ability to understand. General characteristics of the subjects are presented in Table 1.

Balance System (Chattanooga Group, Inc., USA) can be used train balance as well as evaluate balance ability and postural safety with the vertical reaction forces of two 
footplates. For the analysis, we used the measures of left/ right $(\mathrm{L} / \mathrm{R})$ and anterior/posterior (AP) postural sway amplitudes $(\mathrm{cm})$.

Leg length was measured from the anterior superior iliac spine to the medial malleolus using a tape measure with subjects in the supine position to reduce the error of weight distribution due to leg length differences ${ }^{26}$. The subjects were randomly assigned to three groups (self-controlled feedback, yoked feedback, control) with 8 subjects in each. All subjects stood and looked at the monitor of the Balance System. The monitor was positioned at the eye-level of the subjects.

In the acquisition phase, the self-controlled feedback group was provided with feedback when they requested it, whereas the yoked feedback group had no influence on the feedback schedule. Participants in the self-controlled feedback group were informed that they had to control their feedback frequency, and would not receive feedback unless they requested it (active feedback). Participants in the yoked feedback group received visual feedback on the monitor regardless of whether they wanted it or not (passive feedback). Participants in the control group were not given any visual feedback during the experiment. In the retention phase, subjects were not given any visual feedback, to detect the learning effect, one-day after for acquisition trials.

Subjects' left and right feet were respectively placed on one of the two footplates of the Balance System for the measurement. All subjects had to maintain an upright position for 10 seconds on the footplates. All subjects performed 10 acquisition trials per block $\times$ four blocks, to detect the practice effect, and 10 retention trials per block $\times$ two blocks, to detect the learning effect, one-day after the acquisition trials.

The statistical analyses of data were performed using SPSS Ver 12.0 for Windows. One-way analysis of variance (ANOVA) was used to determine the cognitive function differences among the groups as measured by the MMSE (Mini-Mental State Examination). Multivariate ANOVA was used to determine the postural sway differences and interaction effect between groups and blocks in both the acquisition and retention phases. Post hoc analysis was performed using the least significant difference of Tukey's HSD. Statistical significance was accepted for values of $\alpha \leq 0.05$.

\section{RESULTS}

The characteristics of cognitive function of the groups are presented in Table 2 . There was no significant difference in cognitive function among groups as measured by the by Mini-Mental State Examination ( $\mathrm{p}>0.05)$.

There were significant differences in the postural sway amplitudes among the groups $(\mathrm{p}<0.05)$. There were no significant differences in the left/right postural sway amplitudes between blocks ( $p>0.05)$, whereas significant differences in the anterior/posterior postural sway amplitudes $(p<0.05)$. There were no interaction effects between groups and blocks $(\mathrm{p}>0.05)$ (Table 3$)$. Post hoc analysis gave the following results. In the acquisition phase, which was
Table 2. The characteristics of a cognitive function among groups

\begin{tabular}{ll}
\hline Group & Mean \pm SD (Range) \\
\hline Self-controlled feedback & $26.50 \pm 2.33(24.6-28.4)$ \\
Yoked feedback & $27.13 \pm 1.55(25.8-28.4)$ \\
Control & $25.75 \pm 2.38(23.8-27.7)$ \\
\hline
\end{tabular}

Table 3. The comparison of postural sway amplitudes in acquisition phase

\begin{tabular}{lcccccc}
\hline \multirow{6}{*}{ Group } & $\begin{array}{c}\text { Postural } \\
\text { sway }\end{array}$ & $\begin{array}{c}\text { Sum of } \\
\text { aquares }\end{array}$ & df & $\begin{array}{c}\text { Mean } \\
\text { square }\end{array}$ & F & p \\
\hline \multirow{3}{*}{ Block } & LR & 8.291 & 2 & 4.145 & 26.94 & 0.000 \\
& AP & 4.588 & 2 & 2.294 & 11.46 & 0.000 \\
Group * & LR & 0.859 & 3 & 0.286 & 1.86 & 0.140 \\
Block & AP & 2.846 & 3 & 0.949 & 4.74 & 0.004 \\
\hline
\end{tabular}

${ }^{\mathrm{a}}$ LR-left/right, ${ }^{\mathrm{b}} \mathrm{AP}$-anterior/posterior

Table 4. The comparison of postural sway amplitudes in retention phase

\begin{tabular}{ccccccc}
\hline & $\begin{array}{c}\text { Postural } \\
\text { sway }\end{array}$ & $\begin{array}{c}\text { Sum of } \\
\text { aquares }\end{array}$ & df & $\begin{array}{c}\text { Mean } \\
\text { square }\end{array}$ & $\mathrm{F}$ & $\mathrm{p}$ \\
\hline \multirow{2}{*}{ Group } & LR $^{\mathrm{a}}$ & 6.966 & 2 & 3.483 & 14.70 & 0.000 \\
& $\mathrm{AP}$ & 5.559 & 2 & 2.779 & 11.08 & 0.000 \\
Block & LR & 0.026 & 1 & 0.026 & 0.11 & 0.743 \\
& AP & 0.000 & 1 & 0.000 & 0.00 & 0.973 \\
Group* & LR & 0.076 & 2 & 0.038 & 0.16 & 0.853 \\
Block & AP & 0.044 & 2 & 0.022 & 0.09 & 0.916 \\
\hline
\end{tabular}

${ }^{\mathrm{a}} \mathrm{LR}$-left/right, ${ }^{\mathrm{b}} \mathrm{AP}$-anterior/posterior

used to examine practice effect, the left/right and anterior/ posterior body sway amplitudes of both the self-controlled and yoked feedback groups were significantly smaller than those of the control group, but no significant differences were found between the self-controlled and yoked feedback groups.

There were significant difference in the postural sway amplitudes among the groups $(p<0.05)$, but there was no significant difference in the postural sway amplitudes between any of the blocks ( $>0.05)$, and there were no interaction effects between groups and blocks $(\mathrm{p}>0.05)$ (Table 4).

Post hoc analysis gave the following results. In the retention phase, which was used to examine learning effect, the left/right and anterior/posterior body sway amplitudes of the self-controlled feedback group were significantly smaller than those of both the yoked feedback and control groups. In addition, body sway amplitudes of the left/right yoked feedback group was significantly smaller than that of control group. 


\section{DISCUSSION}

We studied the effects of self-controlled feedback on the acquisition and retention of blocked balance training by patients with CVA. Our results show that the left/right and anterior/posterior body sway amplitudes of both the selfcontrolled and yoked feedback groups were significantly smaller than those of the control group in the acquisition phase, which was used to examine the practice effect. In the retention phase, which was used to examine learning effect, the left/right and anterior/posterior in self-controlled feedback group were significantly smaller than those of both the yoked feedback and control groups. The results of the present investigation suggest the importance of selfcontrolled feedback in active participation.

After a cerebrovascular accident, balance and the postural adaptation is generally more difficult. Increased sway during quiet standing, uneven weight distribution with increased weight bearing on the unaffected limb, decreased weightshifting ability in stance, and abnormalities in postural responses have all been documented ${ }^{3,12)}$. Therefore, the evaluation of weight bearing on the lower extremities is carried out before gait training for appropriate functional rehabilitation $^{12}$. Many studies have revealed the characteristics of cerebrovascular accident patients and a comparative studies of cerebrovascular accident patients and normal persons have determined CVA patients' instability of standing posture $\left.{ }^{9}, 10,27\right)$. Many studies have provided feedback for balance improvement of cerebrovascular accident patients ${ }^{3,15)}$. The types of feedback reported are faded $^{28)}$, summary ${ }^{29}, 30$ ), average ${ }^{31)}$, bandwidth ${ }^{32)}$, and frequency feedback ${ }^{17}$, and the frequency and provision of feedback has varied. However, these feedback methods did not encourage active participation of the learner. To address this issue, the efficacy of self-control has been discussed in the field of recognition learning for several years $\left.{ }^{20,} 21,25\right)$. The choice of tool for evaluating cognitive function is very important in the rehabilitation of cerebrovascular accident patients $^{33)}$. Mini-Mental State Examination is available for the evaluation of cognitive function of patients with cerebrovascular accidents $^{31,34)}$. Bassuk et al. ${ }^{35)}$ have shown that MMSE has high reliability $(\mathrm{r}=0.98)$ and validity in the evaluation of cognitive function. The results of the present investigation demonstrate that all subjects understood the experiment, based on the MMSE score, and no differences in MMSE score were found among groups.

The results of this study add to the evidence related to short-term learning effects of self-controlled feedback on balance ability of hemiplegic patients, as reported by Yoon et al. ${ }^{36)}$ In our present study, subjects were assigned to the self-controlled feedback, yoked feedback and control groups, and we compared practice and learning effects of blocked practice among the groups.

We used the acquisition phase to examine practice effect. The left/right and anterior/posterior body sway amplitudes of both the self-controlled and yoked feedback groups were significantly smaller than those of the control group $(p<0.05)$, but no significant differences were found between the self-controlled and yoked feedback groups $(\mathrm{p}>0.05)$.
These results suggest that learning was reinforced through the provision of feedback. In addition, there was significant difference between active practice and passive practice. It is possible that differences in active practice and passive practice were not seen because of the short-term nature of this study.

The retention phase was used to examine learning effect. The left/right and anterior/posterior body sway amplitudes of the self-controlled feedback group were significantly smaller than those of both the yoked feedback and control groups $(\mathrm{p}<0.05)$. In addition, left/right body sway amplitude of the yoked feedback group was significantly smaller than that of the control group $(\mathrm{p}<0.05)$. Wulf et al. ${ }^{21)}$ reported that self-controlled feedback in an active practice was more effective at increasing practice time and learning effect than yoked feedback in a passive practice. The effectiveness of self-controlled feedback was proved by an earlier study ${ }^{20)}$. Our results show that all the parameters of the self-controlled group concerned with balance ability were significantly smaller than those of the yoked feedback and control groups. This result proves effectiveness of active participation by the patient in maintaining balance compared with passive balance training. For the learning effect, unlike the practice effect, the postural sway of the self-controlled feedback group, which carried out active balance training, was significantly smaller than that of yoked feedback group, which carried out passive balance training. This result proves the effectiveness of a training program with active participation at raising the problem solving ability of patients.

One of the limitations of this study was that the present results may not be generalized to all hemiplegic patients as the subjects were recruited by criteria. Moreover, fatigue could not be controlled during the experimental period. In future studies, a controlled environment is required.

The purpose of this study was to examine the effect of self-controlled feedback on the acquisition and retention of blocked balance training by patients with CVA. Our results show that the left/right and anterior/posterior body sway amplitudes of both the self-controlled and yoked feedback groups were significantly smaller than those of the control group in the acquisition phase, which was used to examine practice effect. In the retention phase, which was used to examine learning effect, the left/right and anterior/posterior body sway amplitudes of the self-controlled feedback group were significantly smaller than those of both the yoked feedback and control groups. The results of the present investigation suggest the importance of self-controlled feedback. Therefore, further studies are needed focusing on the development of a self-controlled feedback program for increasing the functional abilities of patients who have disorders of the central nervous system.

\section{REFERENCES}

1) Reginella RL, Redfern MS, Furman JM: Postural sway with earth-fixed and body-referenced finger contact in young and older adults. J Vestib Res, 1999, 9: 103-109. [Medline]

2) Goldie PA, Matyas TA, Evans OM: Gait after stroke: initial deficit and changes in temporal patterns for each gait phase. Arch Phys Med Rehabil, 2001, 82: 1057-1065. [Medline] [CrossRef]

3) Walker C, Brouwer BJ, Culham EG: Use of visual feedback in retraining 
balance following acute stroke. Phys Ther, 2000, 80: 886-895. [Medline]

4) Di Fabio RP, Badke MB: Extraneous movement associated with hemiplegic postural sway during dynamic goal directed weight redistribution. Arch Phys Med Rehabil, 1990, 71: 365-371. [Medline]

5) Rodriguez GM, Aruin AS: The effect of shoe wedges and lifts on symmetry of stance and weight bearing in hemiparetic individuals. Arch Phys Med Rehabil, 2002, 83: 478-482. [Medline] [CrossRef]

6) Sackley CM, Baguley BI, Gent S, et al.: The use of balance performance monitor in the treatment of weight bearing and weight transference problems after stroke. Physiotherapy, 1992, 78: 907-913. [CrossRef]

7) Bohannon RW, Larkin PA: Lower extremity weight bearing under various standing conditions in independently ambulatory patients with hemiparesis. Phys Ther, 1985, 65: 1323-1325. [Medline]

8) Cheng PT, Wu SH, Liaw MY, et al.: Symmetrical body-weight distribution training in stroke patients and its effect on fall prevention. Arch Phys Med Rehabil, 2001, 82: 1650-1654. [Medline] [CrossRef]

9) Bohannon RW, Tinti-Wald D: Accuracy of weightbearing estimation by stroke versus healthy subjects. Percept Mot Skills, 1991, 72: 935-941. [Medline] [CrossRef]

10) Dettmann MA, Linder MT, Sepic SB: Relationships among walking performance, postural stability, and functional assessments of the hemiplegic patient. Am J Phys Med, 1987, 66: 77-90. [Medline]

11) Hesse S, Schauer M, Petersen M, et al.: Sit-to-stand manoeuvre in hemiparetic patients before and after a 4 -week rehabilitation programme. Scand J Rehabil Med, 1998, 30: 81-86. [Medline] [CrossRef]

12) Holt RR, Simpson D, Jenner JR, et al.: Ground reaction force after a sideways push as a measure of balance in recovery from stroke. Clin Rehabil, 2000, 14: 88-95. [Medline] [CrossRef]

13) Mizrahi J, Solzi P, Ring H, et al.: Postural stability in stroke patients: vectorial expression of asymmetry, sway activity and relative sequence of reactive forces. Med Biol Eng Comput, 1989, 27: 181-190. [Medline] [CrossRef]

14) Dickstein R, Nissan M, Pillar T, et al.: Foot ground pressure pattern of standing hemiplegic patients. Phys Ther, 1984, 64: 19-23. [Medline]

15) Engardt M, Ribbe T, Olsson E: Vertical ground reaction force feedback to enhance stroke patients' symmetrical body-weight distribution while rising/sitting down. Scand J Rehabil Med, 1993, 25: 41-48. [Medline]

16) Schmidt RA, Young DE: Methodology for motor learning: a paradigm for kinematic feedback. J Mot Behav, 1991, 23: 13-24. [Medline] [CrossRef]

17) Winstein CJ: Knowledge of results and motor learning: implications for physical therapy. Phys Ther, 1991, 71: 140-149. [Medline]

18) Shumway-Cook A, Wollacott MH: Motor control: Translating research in to clinical practice (3rd ed). Philadelphia: Lippincott Williams \& Wilkins, 2007, pp 21-37.

19) Schmidt RA, Lee TD: Motor control and Learning: A behavioral emphasis. Champaign: Human Kinetics, 2005, pp 565-574.

20) Janelle CM, Barba DA, Frehlich SG, et al.: Maximizing performance effectiveness through videotape replay and a self-controlled learning environment. Res Q Exerc Sport, 1997, 68: 269-279. [Medline]
21) Wulf G, Toole T: Physical assistance devices in complex motor skill learning: benefits of a self-controlled practice schedule. Res Q Exerc Sport, 1999, 70: 265-272. [Medline]

22) Chiviacowsky S, Wulf G: Self-controlled feedback: does it enhance learning because performers get feedback when they need it? Res Q Exerc Sport, 2002, 73: 408-415. [Medline]

23) McNevin NH, Wulf G, Carlson C: Effects of attentional focus, self-control, and dyad training on motor learning: implications for physical rehabilitation. Phys Ther, 2000, 80: 373-385. [Medline]

24) Wulf G, Clauss A, Shea CH, et al.: Benefits of self-control in dyad practice. Res Q Exerc Sport, 2001, 72: 299-303. [Medline]

25) Zimmerman BJ: Self-Efficacy: An essential motive to learn. Contemp Educ Psycho, 2000, 25: 82-91.

26) Perry J: Orthopedic management of the lower extremity in the hemiplegic patient. Phys Ther, 1966, 46: 345-356. [Medline]

27) Shumway-Cook A, Anson D, Haller S: Postural sway biofeedback: Its effect on reestablishing stance stability in hemiplegic patients. Arch Phys Med Rehabil, 1988, 69: 395-400. [Medline]

28) Winstein CJ, Schmidt RA: Reduced frequency of knowledge of results enhances motor skill learning. J Exp Psychol Learn Mem Cogn, 1990, 16: 677-691. [CrossRef]

29) Carnahan H, Vandervoort AA, Swanson LR: The influence of summary knowledge of results and aging on motor learning. Res Q Exerc Sport, 1996, 67: 280-287. [Medline]

30) Schmidt RA, Young DE, Swinnen S, et al.: Summary knowledge of results for skill acquisition: support for the guidance hypothesis. J Exp Psychol Learn Mem Cogn, 1989, 15: 352-359. [Medline] [CrossRef]

31) Hajek VE, Gagnon S, Ruderman JE: Cognitive and functional assessments of stroke patients: an analysis of their relation. Arch Phys Med Rehabil, 1997, 78: 1331-1337. [Medline] [CrossRef]

32) Lee TD, Maraj BK: Effects of bandwidth goals and bandwidth knowledge of results on motor learning. Res Q Exerc Sport, 1994, 65: 244-249. [Medline]

33) Adunsky A, Fleissig Y, Levenkrohn S, et al.: Clock drawing task, minimental state examination and cognitive-functional independence measure: relation to functional outcome of stroke patients. Arch Gerontol Geriatr, 2002, 35: 153-160. [Medline] [CrossRef]

34) Stewart R, Johnson J, Richards M, et al.: Medical Council Cognitive Function and Ageing Study. The distribution of Mini-Mental State Examination scores in an older UK African-Caribbean population compared to MRC CFA study norms. Int J Geriatr Psychiatry, 2002, 17: 745-751. [Medline] [CrossRef]

35) Bassuk SS, Murphy JM: Characteristics of the Modified Mini-Mental State Exam among elderly persons. J Clin Epidemiol, 2003, 56: 622-628. [Medline] [CrossRef]

36) Yoon JG, Kim MH, Yook DW: The effects of self-controlled learning on balance in hemiplegics. J Kor Acad Univ Trained Phys Ther, 2005, 12: 36-44. 